\section{A framework for the evaluation of buildings in the context of climate change for Turkey}

Pelin SARICIOĞLU ${ }^{1}$, ORCID: 0000-0003-0159-0623

İdil AYÇAM², ORCID: 0000-0001-7170-5436

\section{Keywords}

disaster risk reduction; climate change; assessment frameworks; resiliency; buildings

\section{Article Information}

Received:

07.05.2021

Received in Revised Form:

17.07.2021

Accepted:

26.07.2021

Available Online:

29.07.2021

\section{Article Category}

Review Article

\section{Contact}

1. Gazi University, Faculty of Architecture, Ankara, Turkey, pelinsaricioglu@gazi.edu.tr

2. Gazi University, Faculty of Architecture, Ankara, Turkey, iaycam@gazi.edu.tr 


\section{INTRODUCTION}

Climate change can be defined as a type of disaster that develops slowly due to differences in climate averages over 10 years or longer. According to what is defined by the United Nations Framework Convention on Climate Change (UNFCCC), climate change may be reflected "directly or indirectly to people's activity which changes the structure of the global atmosphere and is observed over comparable periods in addition to natural climate variability" (United Nations International Strategy for Disaster Reduction Secretariat, 2008). Among the climatic events related to global warming are; the volatility and extremes of climatic events including precipitation, sea level rise, drought, volcanic activity, hurricanes, biodiversity loss, increased storm intensity, frequent heat waves, changing rainfall patterns, ocean current reversal, and flooding. Since the earth's climate is caused by the earth's surface temperature (Lindsey, 2009), global warming is the primary cause of the change in global climate. For this purpose, these two concepts cannot be separated in any context; the things affecting global warming also affect climate change (Booth et al, 2012). As a result of these disasters, whole or specific parts of society suffer economic, social and physical casualties, and human activities and daily life come to a halt or are disrupted. Moreover, the impacts on the built environment are both structural and non-structural, influencing all three components of a building: material, building systems and inhabitants (distress from overheating), as well as its energy consumption and Greenhouse Gasses emissions (Cere et al,2017; Pidgeon et all, 2011). In this context, the concept of "Resilience" expresses how robust and reliable the buildings are against disasters and sudden shocks, and it reveals the capacity of the buildings to resist the effects of disasters. A resilient building is resistant to any type of disasters and can bounce back in a short time. The idea of a resilience building gets to be conceptually pertinent when constant stresses or sudden stuns debilitate far reaching disturbance or the collapse of physical or social systems (Ahsan, 2013; Basyouni,2017). Because of the evaluation tools developed to measure the resilience of the buildings, the resistance of a building can be measured before the disaster and the necessary measures can be taken to make buildings resistant to disasters (Cimellaro, 2016). Impact, vulnerability-based, integrated, risk management, and adaptation-based approaches to disaster and risk mitigation against climate change effects are grouped under the general heading of assessing the impacts of climate change specifically (Critto, 2016). The objective of these approaches and the resilience assessment tools is basically the same. In this study, a literature review was performed considering the mitigation of the effects of climate change in the context of disaster and risk reduction approaches. The global and modern efforts for creating a national framework about the evaluation of climate change and vulnerability by countries draw attention in the literature. Especially, the effects of climate change, sea level rise on coasts and coastal planning, earthquakes 
and their effects have been studied frequently. Studies that combine social economic vulnerability with physical vulnerability and developing indexes are rare. For example, in USA, a project entitled "Climate Change Impacts on the Housing Infrastructure at Oneida Nation of the Thames" was performed in this field. According to the assessment steps, the climate change risks about buildings are specified, and consequently, the adaptation and mitigation measures are reflected to related sectors and peoples (Pievc Program, 2018).

While there are numerous methods for performing an integrated and complex assessment of risk and vulnerability, the application of these tools is significant because it is directly linked to the assessment's objectives. McEntire et al. (2010) suggested a vulnerability model that included physical science, engineering, and social science studies, as well as the conclusion that a "more complete image of vulnerability is more appropriate to shape inclusive and integrated disaster policies". Climate risk assessments provide an image of prioritized threats based on various scenarios, as well as their relationship to existing adaptation and resilience processes, allowing for more efficient use of available response capability and resources and addressing uncertainty. (Table 1) (Fakhruddin et al., 2020).

Table 1 - Existing Disaster Risk Management and Assessment Tools (Fakhruddin et al., 2020)

\begin{tabular}{|c|c|c|c|}
\hline Discipline & Project title & Author & Brief description \\
\hline $\begin{array}{l}\text { Disaster Risk } \\
\text { Management }\end{array}$ & UK Climate & (NIWA and GNS,2008) & $\begin{array}{l}\text { RiskScape is a regional risk and impact } \\
\text { assessment (001.1t, primary purpose is } \\
\text { to provide a framework in which the } \\
\text { risk of impact to assets due to various } \\
\text { hazards can be catculated. This } \\
\text { information can be used for a wide } \\
\text { range of applications. from planning to } \\
\text { hazard management to asset } \\
\text { management }\end{array}$ \\
\hline $\begin{array}{l}\text { Change Risk } \\
\text { Asessment }\end{array}$ & $\begin{array}{l}\text { Climate Change } \\
\text { Risks in Auckland }\end{array}$ & Climate Change. 2017) & $\begin{array}{l}\text { The UK Government is required under } \\
\text { the } 2008 \text { Climate Change Act to publish } \\
\text { a UK-wide Climate Change Risk } \\
\text { Assessment (CCRA) every } 5 \text { years. The } \\
\text { CCRA will feed in to the development } \\
\text { of the next UK National Adaptation } \\
\text { Programme, expected in } 2018 \text {, as well } \\
\text { as the national adaptation programs of } \\
\text { the devolved administrations }\end{array}$ \\
\hline Asessment & & & $\begin{array}{l}\text { A climate risk assessment to contribute } \\
\text { to the development of Auckland's } \\
\text { Climate Action Plan and relies on the } \\
\text { Auckland Council Climate Change Risk } \\
\text { Assessment (CCRA) } 2019 \text { series of } \\
\text { technical reports. }\end{array}$ \\
\hline $\begin{array}{l}\text { Climate } \\
\text { Change Risk } \\
\text { Asessment }\end{array}$ & $\begin{array}{l}\text { WP3: Small-scale } \\
\text { vulnerability and } \\
\text { risk analysis for } \\
\text { cities and sectors }\end{array}$ & $\begin{array}{l}\text { (Tapia et al.• } \\
\text { 2016) }\end{array}$ & $\begin{array}{l}\text { A high-level climate risk analysis } \\
\text { methodology for urban areas that } \\
\text { provides a top-down. and } \\
\text { broad view of climate risks to cities across } \\
\text { Europe, and takes into account the IPCC } \\
\text { definition'on of Risk including hazard, } \\
\text { exposure and vulnerability }\end{array}$ \\
\hline
\end{tabular}

From the point of Turkey's adaptation against climate change, Batan stated that starting from the question of what global climate change is, general information is given and the causative factors are explained in detail, then the prominent and prominent reports in the literature (UNFCCC, IPCC, Kyoto) are summarized, climate models and future climate scenarios are mentioned. The possible consequences of future climate change have been identified (Batan, 2014). Başkan examines the effects of climate change on physical, chemical and biological degradation mechanisms and presents the results that predict which traditional building materials will be 
affected and how (Başkan, 2016). Bozoğlu made an inquiry about the creation processes and importance of the early warning system to reduce the losses and damages emphasized in the Paris Agreement (Bozoğlu, 2018). In another research's aim is to determine the negative effects of climate change and urbanization on LULC (land use and land cover) and to contribute to sustainable development by developing a spatial planning approach compatible with climate change. As a result, the planning parameters compatible with climate change and the prominent tools in this planning were determined (Onur, 2014). Yildız indicates determining the design parameters that have the most impact on annual cooling energy loads for low-rise apartment blocks in the hot humid climate region of Turkey and to evaluate the uncertainty in the design parameters and annual cooling loads due to global warming (Yıldız, 2012). Dino and Akgül shows the results of climate change impact assessment on a typical mid-rise residential building in four representative cities with different climatic characteristics in Turkey. According to preliminary estimates based on energy simulations, there will be significant overheating in the future, which will have a significant impact on cooling energy demand and/or occupant comfort. The predicted energy consumption also highlights the necessity to investigate climate change adaptation strategies for buildings in the future, as well as the importance of decarbonizing the electrical industry for climate change mitigation (Dino and Akgül, 2019). In addition, Turkish Municipality and Environment and Urban Development has several projects and studies about climate change. For example, greenhouse gas emission inventory, and the preparation of greenhouse gas emission projections were finished. According to Seventh national statement of Turkey's report which have also these projects, they produced action plans for all seven regions of Turkey, and these plans would help those regions adapt to climate change. Smart-city and zero-waste initiatives will become more common. All around the country, new energy-efficient, climate-sensitive residential areas will be built. Houses built by Turkey's Housing Development Administration (TOKI) will be required to install solar panels. They are also working on measures for the most vulnerable sectors to climate change, such as agriculture, livestock, tourism, renewable energy, and industry (RTMEU, 2018). It is concluded that Turkey's climate change action plans are not specific for city or building/building groups.

The literature review indicated that there are several studies for assessing climate change but Turkey has no special framework which is particularly related to the context of building scale and disaster risk reduction. The aim was to create a general evaluation framework by examining the process of mitigating climate change effects in disaster and risk reduction approaches for Turkey. The frameworks evaluating the resilient status of buildings against the climate change impacts were clarified, and criteria of these frameworks were compared with the principles of disaster risk reduction approaches. Furthermore, the evaluation steps were established. Consequently, a general integrated framework for assessing the risky characteristics of buildings has been proposed by comparing and evaluating the disaster and risk reduction approaches to terminate the climate change effects and by considering principles of resilience to disasters.

\section{CLIMATE CHANGE EFFECTS ON TURKEY}

Climate change is considered to be one of the greatest challenges facing humanity in the $21 \mathrm{st}$ century and has serious and global consequences for the environment. There is a significant scientific consensus that the impact of human activities on a changing climate is around $90 \%$, as 
changes are linked to global greenhouse gas emissions from human activities, especially the use of fossil fuels (Smith, 2005).

According to the climate change scenarios RCPs (Representative concentration pathways) published by the IPCC (Intergovernmental panel on climate change), although the effects of climate change vary depending on the location and region in the world, the impacts of climate change will emerge as an increase in temperature, decrease in rainfall, increase in forest fires and increase in flood-tsunami disasters (IPCC, 2007).

Turkey will be affected by the climate change like other global countries. As seen in the Fig. 1, a simulation created by the authors via SIMCLIM3 indicates that Turkey's average temperature will increase nearly $+3-4 \mathrm{C}$ between 1996 and 2100. Although these figures look same, the attribute values' are different in the projection.
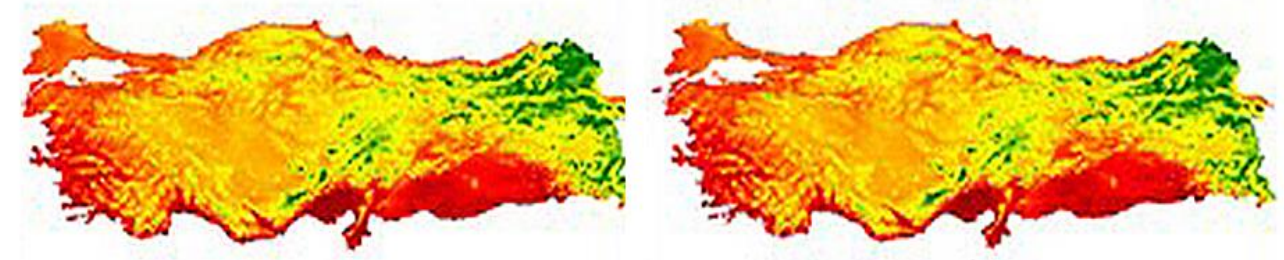

Figure 1 - The SIMCLIM average temperature change projection for Turkey (created by authors)

As can be seen in Fig. 2, the rainfall change for Turkey will tend to fall. This projection is also made by SIMCLIM. Therefore, according to all projections about Turkey, the average temperature tends to increase and rainfall tends to decrease, which can be an early warning for Turkey before the country becomes a desert. Fig.1 and Fig. 2 demonstrates that climate change effects for Turkey should be evaluated before the risks will increase. In this context, the disaster risk and reduction approaches against climate change effects can be used as guideline.
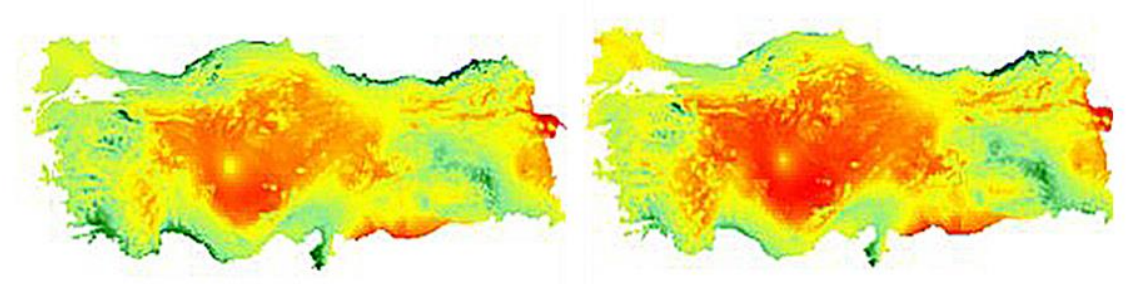

Figure 2 - The SIMCLIM Average Rainfall Change Projection for Turkey (created by authors)

Other climate-related risks for Turkey include river flood, coastal flood and wildfire, respectively. The simulations by the open access website "ThinkHazard" show predictions for next 10 years. 

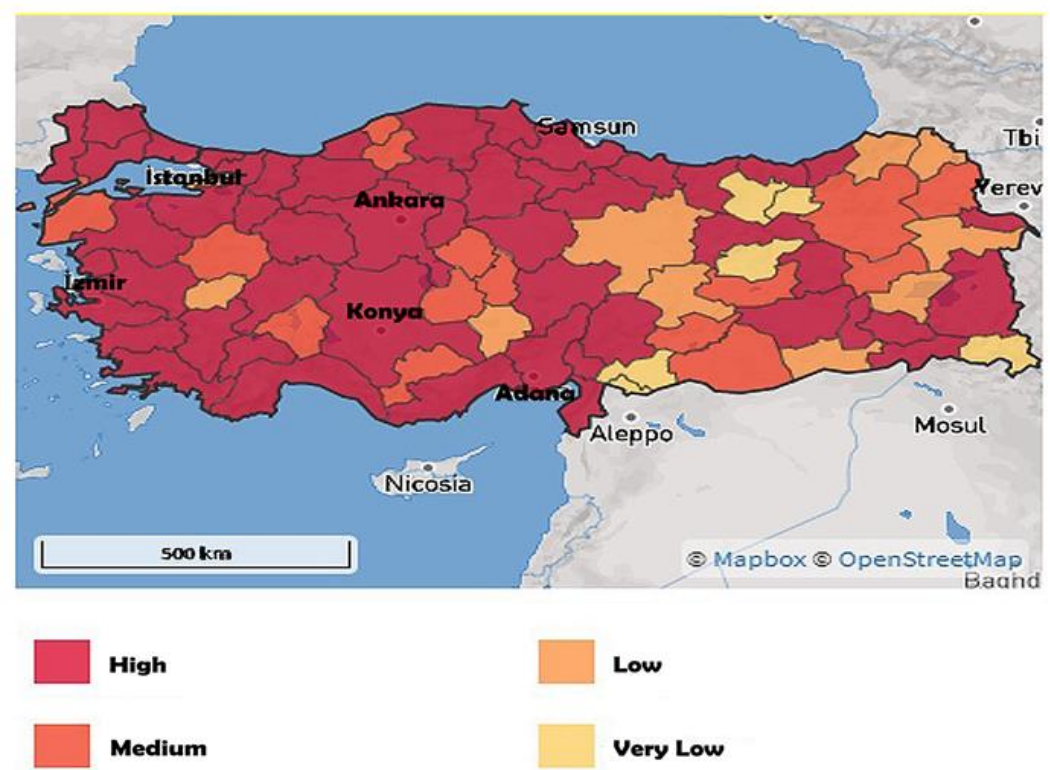

Figure 3 - The River Flood Risk in Turkey in the next 10 Years (Thinkhazard, 2020)

As seen in the Fig. 3, the river flood risk for Turkey is approximately high, meaning potentially damaging and life-threatening river floods are expected to occur at least once in the next 10 years. According to Fig. 4a, Turkey's coastal flood hazard is considered to be high based on currently available data, which means that potentially-damaging waves are expected to flood the coasts at least once in the next 10 years. Accordingly, the impact of coastal flood must be considered in different phases of the project for any activities to be performed near the coasts (Thinkhazard, 2020).

According to Fig. 4b, Turkey's wildfire danger is very strong for the next ten years, with a chance of more than $50 \%$ of seeing conditions that can sustain a major wildfire that can result in both life and property loss in any given year. (Thinkhazard,2020).
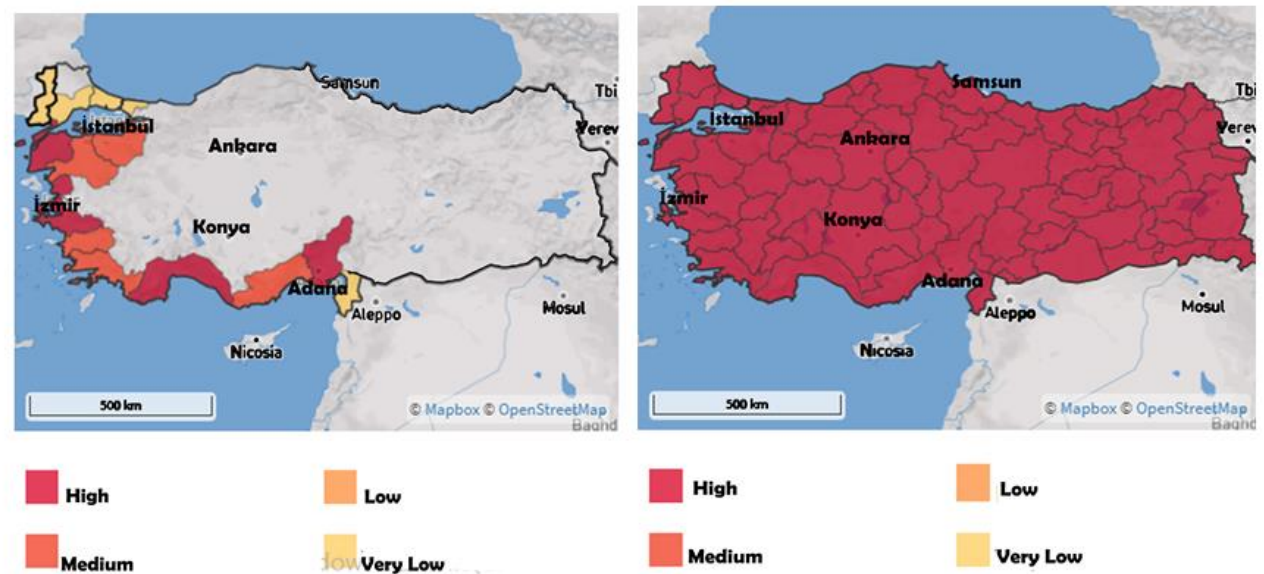

Figure 4 - (a) The Coastal Flood Risk in Turkey in the next 10 years, (b) The Wildfire Risk in Turkey in the next 10 years (Thinkhazard, 2020) 


\section{DISASTER RISK REDUCTION APPROACHES AGAINST CLIMATE CHANGE}

The role of cooperation and coordination of organizations involved in disaster management in Turkey is assigned to the Disaster and Emergency Administration (DEMP, 2019). According to DEMP's definition, the affected society has insufficient coping capacity. "Disaster is not an event itself; it is the result". According to the disasters around the world, meteorological disasters constitute 28 of 31 natural disaster types (DEMP, 2019).

It is important to know the approaches of disaster risk reduction because the results of disasters can be prevented when considering the disasters as a risk at first. "Disaster risk is defined as the probability of loss of life, injury or destruction and damage from a disaster in any specific period." Therefore, disaster risk is defined as the frequency and severity of a hazard combined, the number of people and valuable objects facing the hazard, and their sensitivity to damage (PreventionWeb,2015). The aforenoted components are described by the IPCC (IPCC, 2018) as follows:

"Hazard" refers to the possibility of a natural or human-caused physical occurrence or pattern that may result in the loss of life, injury, or other health consequences, as well as harm and loss to property, facilities, livelihoods, service provision, habitats, and environmental resources People, livelihoods, organisms or habitats, environmental functions, facilities, and resources, infrastructure, or economic, social, or cultural assets in places and settings that may be negatively impacted are all examples of exposure. Vulnerability is a term that describes a person's proclivity or predisposition to be harmed. Vulnerability includes a wide range of definitions and elements, such as vulnerability to harm and a lack of ability to cope and adapt. (Viner et al., 2020).

All of these definitions are critical for disaster risk reduction which indicates structural and nonstructural measures and activities that must be ensured before, during and after the disaster to avoid or mitigate effects of natural, technological and human-induced hazards and environmental degradation (DEMP, 2019).

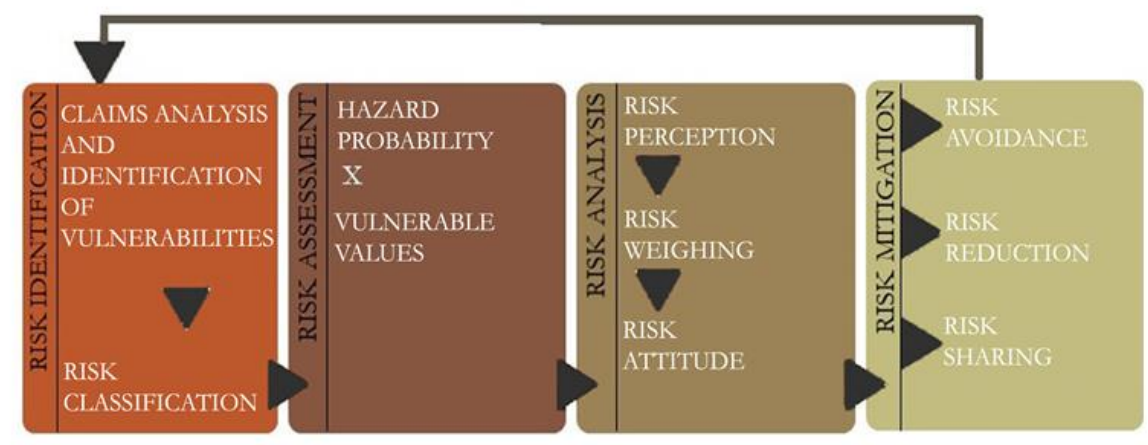

Figure 5 - A General Framework of Disaster Risk Management and Reduction (Balaban, 2009)

As can be seen in Fig. 5, disaster risk reduction and management process has certain steps. This figure is about a schema of a general framework about disaster risk management; accordingly, the 
risk management is the primary element of disaster risk reduction and also as important as disaster risk reduction itself. Additionally, disaster risk management indicating the application of disaster risk reduction policies and strategies to prevent new disaster risks reduces existing disaster risks and manages residual risks, contributing to strengthening of resilience and reduction of losses (UnSpider, 2021).

\subsection{Disaster Risk Reduction Approaches}

In the face of global environmental change, reducing risk from natural hazards is a major challenge now and in the future. The danger and risks to human security posed by natural hazards cannot be minimized solely by concentrating on the hazards, which is becoming clearer. Societies would be forced to adapt to changing environmental factors, necessitating the development of resilience through the reduction of natural hazard vulnerabilities. Natural hazard and climate change vulnerability assessment has become a common research topic in recent decades (Birkman et al, 2013; Chambers, 1989).

DRR (disaster risk reduction) and CCA (climate change assessment) are two policy priorities that are closely linked, despite the fact that they have previously worked independently (Lei and Wang, 2014; Gero et al, 2011; Gero et al, 2011). Topics of these two policy priorities, including flood control, do, however, overlap. Furthermore, methods used to achieve a policy objective can be useful in achieving another. For instance, policies developed for disaster risk reduction can make contributions to climate change assessment. On the other hand, climate change assessment techniques and strategies such as vulnerability assessments can back up disaster risk reduction (Papathoma et al, 2016).

Although engineering and ecological resilience are the most well-known forms of resilience (Folke, 2006; Holling, 1996) resilience is also becoming more prevalent in other areas, such as disaster risk management and reduction as well as social sciences. A single-state equilibrium perspective of resilience is often used in disaster-risk mitigation approaches, similar to engineering. The approaches of disaster risk reduction against climate change aim to internalize climate change impacts and minimize the losses. In other words, these approaches help reduce the vulnerability of communities, buildings and countries against the climate change.

The approaches of disaster risk reduction against climate change have five different assessment methods $(\bullet$ Impact $\bullet$ Vulnerability Based $\bullet$ An integrated $\bullet$ Adaptation Based $\bullet$ Risk management Approaches). While first four are traditional research methods, fifth one which is risk management emerged when CCIAV (Climate change impact assessment vulnerability) studies began to be addressed in disaster-related policy making processes. In the Table 2, it is shown these approaches' brief purpose and scales.

- Impact approach; the aim of this approach is to evaluate the possible climate change effects under a specific scenario and evaluate the need for adaptation and / or mitigation to decrease vulnerability to climate risks. The term impacts is used in this study to refer to the effects of extreme weather and climate events, as well as climate change, on natural and human systems. It is often referred to as a top-down method because it combines scenarios scaled down from global climate models to local scale with a sequence of empirical measures beginning with the 
climate system and progressing through biophysical effects to the socio-economic assessment (IPCC,2014).

- Vulnerability approach; Vulnerability is a broad term with numerous meanings (Kelly and Adger, 2000). However, the Intergovernmental Panel on Climate Change (IPCC) concept of vulnerability as a feature of a system's exposure, sensitivity, and adaptive capability (IPCC, 2001; IPCC, 2007) has recently been widely used in the context of climate change (Basset and Fogelman, 2013; Opah et al, 2020). Vulnerability varies greatly amongst people, industries, and regions. The diversity of the 'real world' is the starting point for assessing vulnerability. Differentiating across scales makes conceptual and analytical challenges easier to understand:

- International comparisons of vulnerability frequently rely on national factors, such as grouping less developed countries or comparing human development progress among countries with similar economic circumstances.

- Vulnerability assessments help determine development priorities and track success at the national level. For strategic development plans, sectoral assessments provide additional detail and targets.

- Vulnerable groups can be identified and coping measures applied at the local or community level, frequently through participatory methods (Downing et al, 2003).

It focuses on the sensitivity of the target by considering the orientation to harm, then trying to maximize the potential advantages and minimize potential harm. Since the vulnerability is highly context and scale dependent, efforts must be made to clearly identify its derivative and significance, as well as to examine the uncertainties discovered in vulnerability assessments (Critto, 2016).

- The concept of vulnerability as defined by IPCC has been expanded to include both the social vulnerability and it has been proposed to combine it with risk assessment.

Table 2 - Disaster risk reduction approaches' purposes and scales

\begin{tabular}{|l|l|l|}
\hline CCIAV Approaches & Purpose & Field of interest \\
\hline Impact Approach & $\begin{array}{l}\text { Seek to characterize, diagnose, and } \\
\text { project risks or impacts of } \\
\text { environmental change }\end{array}$ & $\begin{array}{l}\text { People, communities, economic } \\
\text { activities, infrastructure, } \\
\text { ecosystems, or valued natural } \\
\text { resources }\end{array}$ \\
\hline Adaptation based Approach & $\begin{array}{l}\text { Assessment of total system } \\
\text { integrity; it considers the capacity of } \\
\text { the entire socio-economic and } \\
\text { ecological network }\end{array}$ & $\begin{array}{l}\text { Any given region or sector to adapt } \\
\text { to climate change }\end{array}$ \\
\hline Vulnerability Approach & $\begin{array}{l}\text { Specifying the weaknesses against } \\
\text { climate change }\end{array}$ & $\begin{array}{l}\text { Community, country, people group, } \\
\text { region, local areas, buildings }\end{array}$ \\
\hline Integrated Approach & $\begin{array}{l}\text { Modelling and other procedures for } \\
\text { investigating CCIAV }\end{array}$ & $\begin{array}{l}\text { Mathematical model-based } \\
\text { different disciplines }\end{array}$ \\
\hline Risk Management Approach & $\begin{array}{l}\text { Identifying potential problems } \\
\text { before they occur }\end{array}$ & Any given sector \\
\hline
\end{tabular}


- Adaptation approach: it is directly associated with risk management by investigating the adaptation measures and adaptive capacity needed for improving robustness or resilience of a system facing climate change. This approach focuses on an activity where stakeholders participate to develop decision-making rather than a research-based activity. The key progress here is the inclusion of adaptation to the previous and current climate. Adaptation solutions come in a variety of shapes and sizes, based on a community's, business's, organization's, country's, or region's specific situation. There is no 'one-size-fits-all' solution-adaptation might include everything from flood defenses to cyclone early warning systems to converting to drought-resistant crops, as well as rethinking communication networks, business operations, and government policies (UNFCC, 2021).

- Risk management approach: it specifically focuses on decision-making and provides a practical guide to evaluating various research concepts and techniques described, despite conflicting with the uncertainty assessment common in CCIAV evaluation. The risk is usually assessed as the probability and a combination of consequences of an event. Topics to assess include evaluating current adaptations to climate variability and extremes prior to addressing adaptive responses to future climate, associating adaptation with sustainable development, stakeholder engagement, evaluating adaptation limits, and taking uncertainty decision (Critto, 2016).

- Integrated approach: This approach represents crucial experiences and feedbacks by combining assessment modeling and other methods of examining CCIAV through disciplines, industries, and scales. Integrated climate risk management could provide a framework to allow the disaster community to move beyond the still dominant focus on preparedness and response and for the adaptation to climate change community to move beyond the design of hypothetical future adaptation strategies Integrated evaluations can include one or more mathematical models, as well as an integrated evaluation process that connects various fields and individuals. Managing uncertainty in integrated evaluations may utilize models including simple models associating large-scale processes, via intermediate complexity models, and the complex, physically explicit representation of Earth systems. The trade-offs between realism and resilience characterize this framework, with non-complex models being more flexible with less details and complex models having more details and a wider range of results. For objectives such as national assessments, economic and commercial trade impact analysis, and joint population and climate study, cross-sectoral integration is needed (Critto, 2016), (UNDP ,2002).

Vulnerability assessment approach is critical and used for building scale the most. As mentioned above, vulnerability assessment is used for certain goals including the assessment of physical vulnerability or social-economic vulnerability against the climate change effects.

The evolution of approaches to assessing vulnerability has become an emerging concept for climate science and policy over the past few decades. Climate change affects both exposure and sensitivity and therefore creates potential climate effects, which in turn increases vulnerability. Adaptive capacity, which includes technological, socio-economic and educational capacities, has the potential to reduce vulnerability. Vulnerability assessments are used to generate data that can be used to learn 
how a system is potentially influenced by and responds to changes in climate conditions, as well as to contribute to policy-making by presenting important information to stakeholders and recommending adaptation steps. It also offers input to stakeholders' decision-making processes about how to respond to the impact of global change and promote long-term growth.

Vulnerability assessments are important for specifying physical resistance against climate change particularly on the building scale (Tanık and Tekten, 2018).

The rate of loss of a specific element or group of elements within a compromised area is referred to as a physical vulnerability. It is measured on a scale of 0 (no loss) to 1 (significant loss) (total loss). Additionally, although it is called "physical", the vulnerability of buildings emerges due to social, economic or cultural reasons. It is clear that it depends on a large number of potential factors. (Kantamaneni, 2017).

From the point of disaster risk, vulnerability assessments of disasters related to climate change are assessed with some methods. For example, the evaluation of vulnerability of flood risk on the coastal areas, there are some specific methods are used for assessment. These are array-based methods, indicator-based approaches, GIS6 based decision support systems and dynamic computer models. Moreover, existing flood risk assessment studies and damage models use an experimental approach based on post-event damage data collection to identify vulnerability functions, or synthetic approaches where vulnerability functions are based on expert opinion (Kantamaneni, 2017).

Other assessments as vulnerability are social and economic assessments. In general, using the indexes called "assessment index" aims to evaluate these risks. The SoVi (social vulnerability assessment index) index is used for social vulnerability assessments against climate change effects. This index identifies potential social burdens. Additionally, the EVI (economic vulnerability index) is used for evaluating the countries' physical vulnerability against economic and environmental risks. Additionally, various versions of the EVI index have been produced in recent years and applied to various geographical regions. The EVI consists of eight socio-economic indicators divided into several subgroups (Kantamaneni, 2017).

All in all, evaluating the disaster risks against climate change effects is complicated and requires certain steps.

\subsection{Resiliency Frameworks for Buildings}

"Resilience" is derived from the Latin word "resiliere," meaning "bouncing back." The common use of the term "resilience" reflects the capacity of a system or entity to return to typical condition after the event of an occasion that disturbs its state. Such a wide definition applies to such differing areas as biology, materials science, brain research, financial matters, and building (Hosseini et.al, 2016).

Initially, four academic areas regarding resilience are identified as follows: social sciences, engineering, ecology and disaster risk reduction. In this context, while "resilience" in the field of engineering is about the ability of a system to recover, its definition in the field of ecology suggests 
that the system has more than one balance. When a steady state is required for the load-bearing ability of building foundations and the strength of a building, engineering resistance is appropriate.

Resilience in the disaster risk mitigation sector assesses resilience in terms of the social, economy, and physical recovery from a dangerous event to a single state, and measures the likelihood of a dangerous event, represents the internal and external vulnerabilities of societies, cities and buildings and measures the likelihood of a dangerous event. (Redman, 2014; Rajkovich and Okour, 2019).

The significance of flexibility in disaster risk management / reduction was emphasized in 2005 by UNISDR (United Nations International Strategy for Disaster Risk Reduction) with the adoption of the Hyogo Declaration. The 10-year Hyogo framework for action offered guidance to different industries and stakeholders in establishing disaster risk mitigation legal and institutional structures. Actions included assessing and monitoring risks, establishing a safety and resilience Sendai Framework action priorities such as understanding the disaster risk, strengthening disaster risk management.

As seen in Fig. 6, while resilience tools are mostly developed for residential buildings, it points out that there are many tools for various type of buildings. Most of them have criteria for both existing buildings and new buildings. Moreover, most of them use the rating method as an evaluation system. Among these tools, the focus on building and building systems includes B-READY, ENTERPRISE, NIST, NYSERDA, BOSTON, NEW YORK CITY, FORTIFIED and REDI. Additionally, while some of these tools evaluate the building scale as well as city and regional scales, some of them only evaluate the building scale.

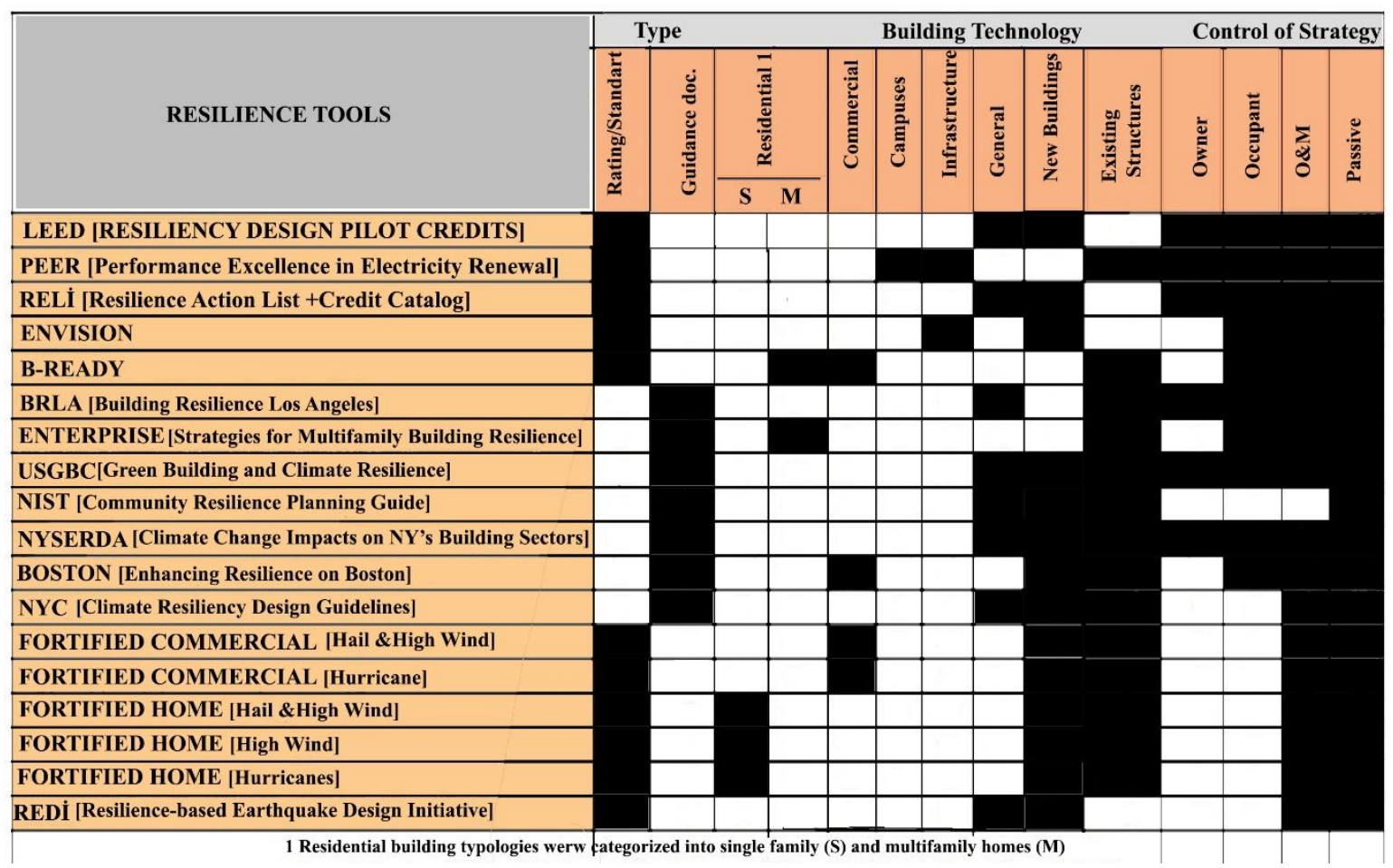

Figure 6 - Resilience frameworks and principles (Rajkovich and Okour, 2019) 
In addition, while some focus on more than one type of disaster, some are created according to a single type of disaster. The B-READY building resilience assessment instrument of DNV-GL (Oslo, Norway), for example, provides an evaluation of local environment hazards as well as a building's vulnerability and resilience to include a resilience index, as shown in Fig. 7 (based on a 0-100 scale). In addition, the assessment tool makes recommendations for resilience steps. The tool investigates the twelve building systems, including flexibility measures such as building envelope and structure, mechanical systems and controls, electricity and lighting and 130 durability measures including operations and community (DNV-GL, 2020).

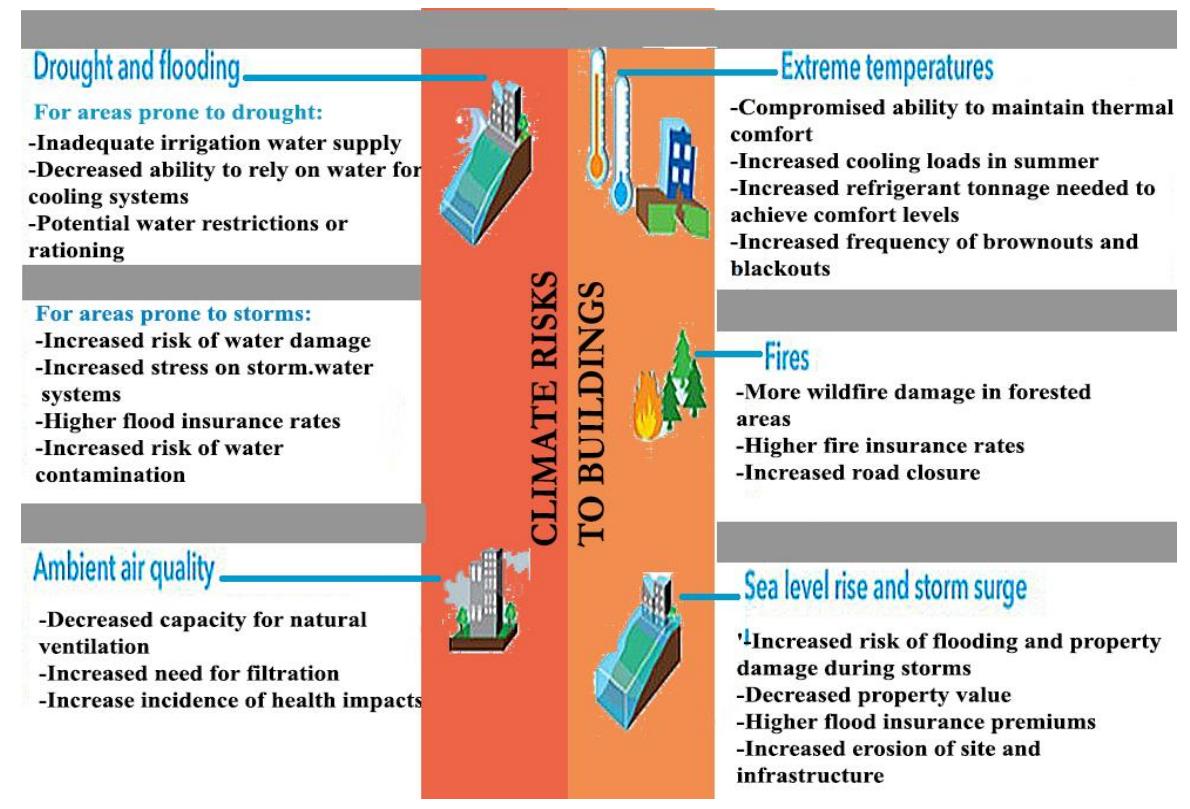

Figure 7 - B-Ready tool's recommendations against climate change effects (DNV-GL, 2020)

As seen in Fig. 8, the B-Ready tool has some steps for evaluating the resiliency of a building. These steps are necessary for getting a final assessment report.

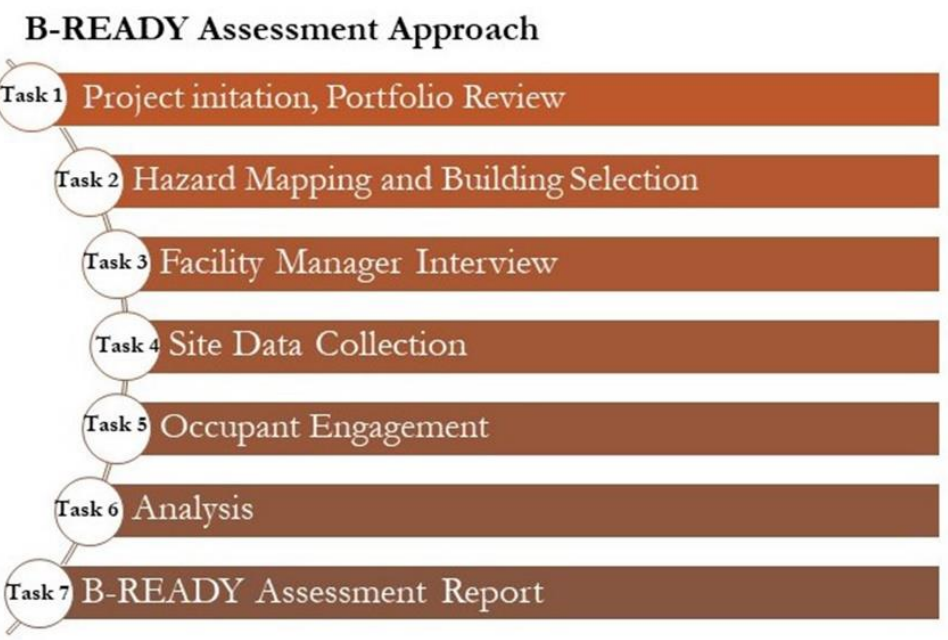

Figure 8 - B-Ready resilience tool's evaluation steps (DNV-GL, 2020) 
As conclusion, the goals of resilience tools and disaster risk reduction approaches against climate change are preparing the buildings against disasters, reducing the climate risks.

As mentioned previous section, Turkey has no framework for assessing the climate risks and as mentioned above sections in article, the assessment tool or framework for climate change disasters are important to construct suitable buildings. This framework is a general framework for evaluating the climate change impacts. Also, this framework is modified from other frames such as climatic risk management frameworks (Fig. 9) (Escarameia and Tagg, 2021).

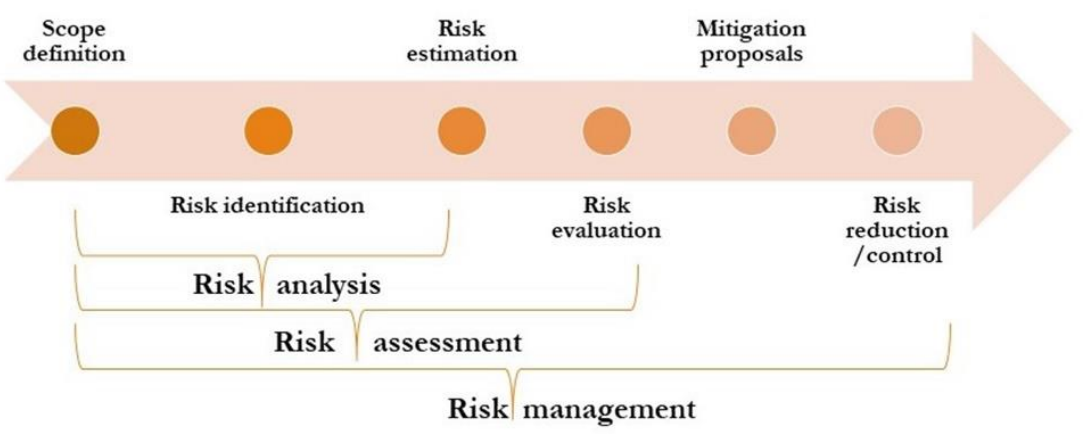

Figure 9 - Flood risk management framework steps (Escarameia and Tagg, 2021)

\section{A FRAMEWORK PROPOSAL FOR EVALUATING THE CLIMATE RISKS FOR TURKEY}

As mentioned in section 3, these climatic risks evaluation framework is adapted from other frameworks. Although it is not unique framework in the literature, there is no study as means of suggestion as framework for Turkey.

In this context, as seen in the Fig. 10, the proposal framework requires these steps;

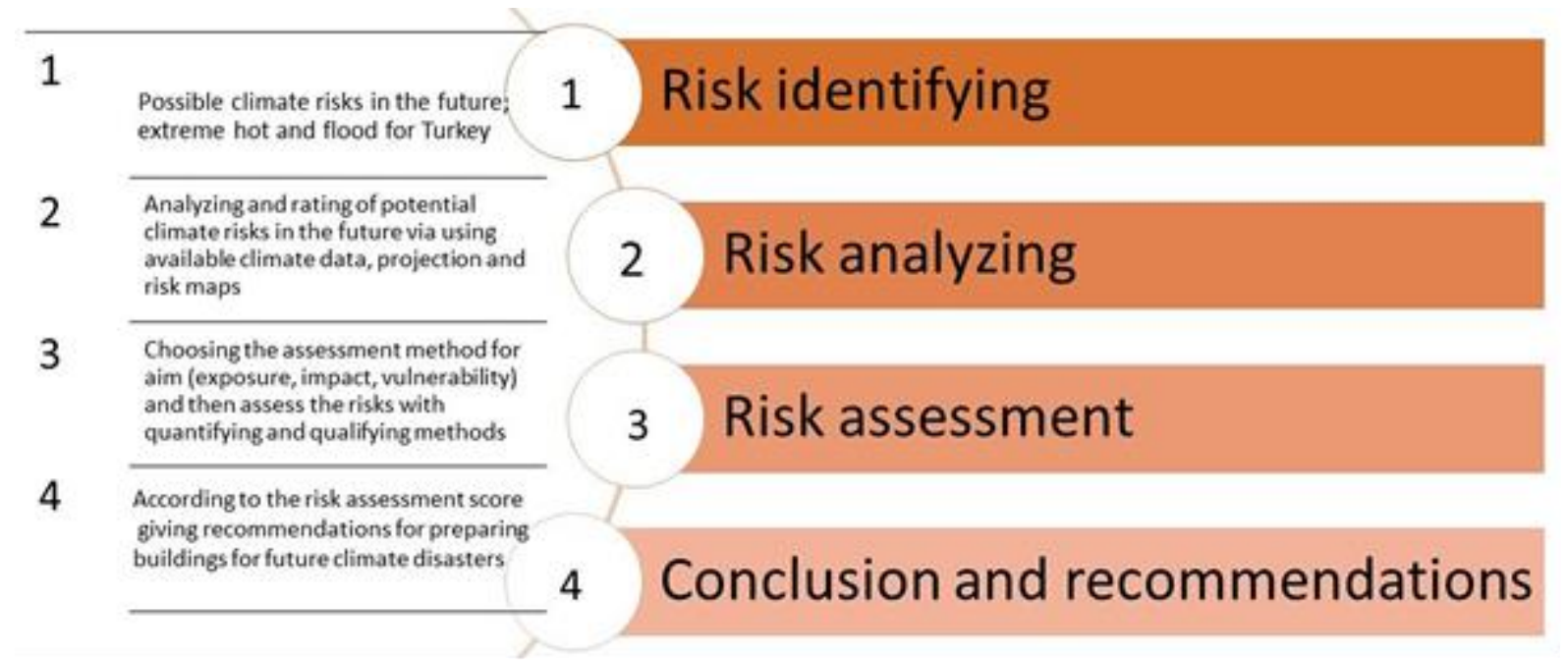

Figure 10 - The proposal framework for climate risks for Turkey (created by authors) 
1- Risk identifying; For this step, as mentioned in the literature, risk maps and databases created on the basis of disasters experienced in the past are used. Since possible risks in the future will be handled within the scope of the subject, it is thought that simulations can be made by using the regionally scaled versions of global climate projections. It is necessary to search for Turkey's all climate projections, specify the possible risks for the high risk field and implement this framework. Furthermore, the stages of risk identifying can be classified as follows: as Köhler et al. (2016) mentioned in the CRAM framework; hazard type, scale, limits, elements considered to be exposed to risk and risk metrics.

2- Risk analyzing; It is the most important stage of risk assessments where the nature of the risks is understood and the risk level is determined. This process can be conducted with qualitative and quantitative methods. Due to data limitations in the literature, a qualitative approach is typically favored when evaluating impact, hazard and risk (access limitation, none). However, qualitative assessments can involve a high level of uncertainty requiring definition.

Furthermore, the results regarding such a risk assessment are challenging to utilize to compare the two regions because the risk assessment is subjective in terms of experts' opinions. Since the study is thought to be user-focused, it is thought that qualitative analysis may be appropriate for risk analysis.

3- Risk assessment; The steps within the risk evaluation do not take place in tandem over time, but they are generally practiced at the same time. For instance, the risk assessment procedure should begin while risk identification process is conducted. More precisely, the risk assessment working group must establish risk assessment parameters to determine if a risk is high, medium, or low. Then decisions should be taken about what degree of risk to consider. Actions must be based on risk levels.

In the study, making vulnerability risk assessment at building scale against the determined effects of climate change was considered. For that purpose, the vulnerability parameters related to buildings were determined by dividing the vulnerability parameters into two (structural and nonstructural) categories as guided in the other indexes and also by using international indexes and frames, and then the questionnaire and expert teams could decide how important each parameter and their scoring was, and finally, the building phase would be applied in a user-oriented manner. It is expected to specify a vulnerability level and score. The result is thought to be suitable for creating adaptation and mitigation proposals for the building according to the level to be determined initially.

4- Conclusion and recommendations; After the 3rd step, the result of evaluation was used for determining the levels according to the scores determined by the experts. According to the 3rd step's conclusions, climate risk reduction recommendations are mentioned to skate holders, users or designers. As mentioned in the 3rd step, the recommendations are provided up to a certain level of risk. The levels can be categorized as 3 steps as an example: low, medium and high.

As seen in Fig. 11, the framework which aims to assess climate risks for Turkey is explained in detail. According to the first step, 'the risk identifying step' includes extremely hot weather, flooding and wildfire for Turkey according to the simulations. Thus, the scale is about building; the extent 
is a specified area which will be determined based on risk maps. The risky elements are thought to be buildings and its environments. The risk metric is measured as affected number of buildings and people.

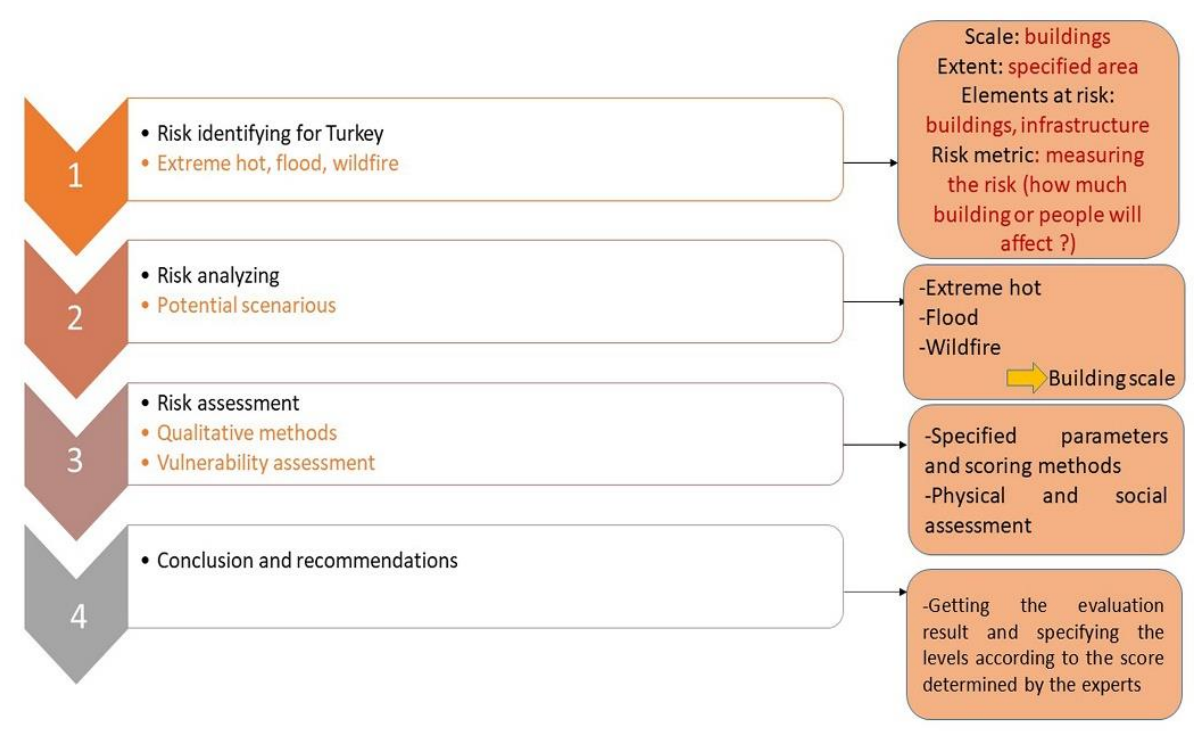

Figure 11 - The proposal framework's detailed steps (created by authors)

The second step related to risk analyzing includes potential climate risks for Turkey and for buildings. At this step, it is concluded that an expert team is necessary for creating a scoreboard as qualitative assessment. It is thought that a Likert scale can be using for the frame. A rating scale called a Likert scale is used to analyze people's opinions, attitudes, and behaviors. In survey research, Likert scales are popular because they make it simple to operationalize personality traits or perceptions. Some of the most common types of items include: Agreement: Strongly agree, Agree, Neither agree nor disagree, Disagree, Strongly disagree. Quality: Very poor, Poor, Fair, Good, Excellent. Likelihood: Not at all likely, Somewhat likely, Extremely likely. Experience: Very negative, Somewhat negative, Neutral, Somewhat positive, Very positive (Scribbr, 2020). In the study, 5-point Likert scale which includes "Very poor, Poor, Fair, Good, Excellent " can be used. The expert team decide the points for each building' part. In addition, this scale is usually preferred by assessment teams. For example, in the "Climate change impacts on the housing infrastructure at Oneida Nation of the Thames" project expert teams used a 5-point Likert scale for assessment the risk (Table 3) (PievcProgram, 2018). 
Table 3 - Example of a Likert scale (PievcProgram, 2018)

\begin{tabular}{|c|l|}
\hline Score & Description \\
\hline 0 & $\begin{array}{l}\text { Negligible } \\
\text { Not applicable }\end{array}$ \\
\hline 1 & $\begin{array}{l}\text { Highly unlikely } \\
\text { Improbable }\end{array}$ \\
\hline 2 & Remotely possible \\
\hline 3 & $\begin{array}{l}\text { Possible } \\
\text { Occasional }\end{array}$ \\
\hline 4 & $\begin{array}{l}\text { Somewhat likely } \\
\text { Normal }\end{array}$ \\
\hline 5 & $\begin{array}{l}\text { Likely } \\
\text { Frequent }\end{array}$ \\
\hline
\end{tabular}

Because in this step, it should be determined which climate risk affected the buildings and their elements, and the degree of this effect should also be revealed. According to the climate scenarios mentioned in other sections, extremely hot weather conditions will affect the buildings more than flooding for Turkey.

The third step named "risk assessment" is the most important one because the total score will be determined based on the result of this step. For this step, it is thought that vulnerability assessment will be made. Moreover, buildings will be assessed in two parts: structural and non-structural assessments will be made. The structural module includes columns, beams, walls, floor slabs and foundations that form part of the structural system of buildings. The other part contains architectural security, infrastructure protection, access and physical security, critical systems, and equipment and supplies.

For the last step which is the conclusion and recommendations, contents about climate risks mitigation are presented.

\section{CONCLUSION}

According to this framework and the scenarios for Turkey, it is concluded that extremely hot weather will affect the buildings' energy consumption because the weather degree will rise; therefore, efficient cooling systems and building elements such as cool roof, cool materials for facades and other elements of buildings will be necessary. Furthermore, extreme heat cycles are often followed by a rise in the peak energy demand for active building cooling, which often correlates with a more difficult process in obtaining sufficient cooling water for generating thermal power under extremely hot conditions. 
In terms of flooding, buildings in Turkey's coastal areas will be at risk. Buildings that received damage from coastal flooding often bear the traces of wind damage as well. Water driven by hurricane-force winds may penetrate a building through particularly sealed openings, and rain penetrating through a damaged roof can damage the indoor area and in some cases expose the building to dangerous water-borne pathogens. In the planning process, all sources of damage, especially those related to water penetration into the building envelope, should be considered. It should be noted that coastal flooding is not the only reason for direct physical damages caused by tropical cyclones and other weather events. Accordingly, all weather hazards identified during the design and planning stages result in adequate risk management for the building projects. Therefore, in Turkey, buildings should be designed considering these risks.

When it comes to the impact of wildfire risk on structures, the manufacturing method for materials used for framing and façades, as well as non-combustible materials for both, should be considered. Traditional construction methods utilizing either one or both of steel and concrete are reliable in wildfire on the condition that these structures are well sealed to prevent firebrand entry. These techniques should be used for local construction examples which not only meet local building requirements but also resist to wildfire attack.

A framework used for assessing the climate change risks and providing recommendations to skate holders, users or designers for the readiness of buildings against climate change risks was proposed in this study.

By examining and comparing the approaches, it was concluded that disaster risk reduction approaches and resiliency frameworks have similar aims and similar criteria for assessment.

In this context, the proposed framework for Turkey is created by combining these approaches and frameworks. However, there are some issues that have to be reconsidered about the framework;

-Adaptation to relevant areas should be ensured because of Turkey's different climate zone, meaning framework should be resilient.

-The evaluation parameters regarding the framework should be changed according to the building function. For example, hospital buildings require much more criteria than residentials.

-This framework includes and suggests only physical assessment of a building, but other parameters such as economic and social factors should be integrated to the framework for an expanded and efficient assessment. Getting a versatile framework means having more prepared buildings against future climate.

It is concluded that this framework highlights the climate risks for Turkey and will encourage the designers, experts and skate-holders for creating the local assessment framework. Furthermore, by paying attention to future weather conditions, it is necessary to update the building and construction regulations considering climate risk assessment and management, meaning Turkey needs a new perspective for the construction sector. 


\section{Conflict of Interest Statement}

There is no conflict of interest for conducting the research and/or for the preparation of the article.

\section{Financial Statement}

No financial support has been received for conducting the research and/or for the preparation of the article.

\section{Ethical Statement}

This work is an original work. We act in accordance with scientific ethical principles and rules in all stages of the study, including preparation, data collection, analysis and presentation of information; that we refer to all data and information not obtained within the scope of this study and that we include these sources in the bibliography; we accept that we do not make any changes to the data used and declare that we comply with ethical duties and responsibilities.

\section{Author Contribution Statement}

\begin{tabular}{|l|l|l|}
\hline A. Idea, Concept & B. Study Design, Methodology & C. Literature Review \\
\hline D. Supervision & E. Material, Resource Supply & F. Data Collection, Processing \\
\hline G. Analyses, Interpretation & H. Writing Text & I. Critical Review \\
\hline
\end{tabular}

AUTHOR 1: A/B/C/E/F/G/H

AUTHOR 2: A/B/D/G/I 


\section{REFERENCES}

Ahsan, S. M. M. (2013). Resilient cities for the poor or by the poor. (Master of Science). A case study from Bangkok. Technische Universität, Berlin. Retrieved from: https://www.urbanmanagement.tuberlin.de/fileadmin/f6 urbanmanagement/Study Course/student work/Thesis Ahsan Re silient Cities for the Poor or by the Poor.pdf.

Balaban, S.. M. (2009). Risk society and planning: the case of flood disaster management in Turkish cities. (Philosophy of Doctorate Thesis). Middle East Technical University, Ankara.

Bassett, T.J.; Fogelman, C. (2013)Déjà vu or something new? The adaptation concept in the climate change literature. Geoforum, 48, 42-53. Retrieved March 28, 2021, from: https://doi.org/10.1016/j.geoforum.2013.04.010.

Basyouni, M. E. (2017). Resilient Buildings: A Path towards Adaptability Climate Change Adaptation Strategies and Interventions for Buildings Resilience. International Journal of Current Engineering and Technology, 7, 12. Retrieved from: https://inpressco.com/wpcontent/uploads/2017/04/Paper25481-492.pdf.

Başkan, E.G. (2016). A Proposed model for understanding the impacts of climate change on tangible cultural heritage. (Doctoral dissertation). Middle East Technical University, Ankara.

Batan, M. (2014). Global climate change and its expected consequences (Doctoral dissertation). Dicle University, Diyarbakır.

Birkmann, J., Cardona, O. D., Carreño, M. L., Barbat, A. H., Pelling, M., Schneiderbauer, S., ... \& Welle, T. (2013). Framing vulnerability, risk and societal responses: the MOVE framework. Natural hazards, 67(2), 193-211. Doi: 10.1007/s11069-013-0558-5.

Booth, C. A., Hammond, F. N., Proverbs, D. G., Lamond, J. (2012). Solutions for climate change challenges in the built environment (Digitally). United States: John Wiley \& Sons.

Bozoğlu, B. (2018). What Turkey Should Do About the Early Warning System under the Paris Climate Agreement. (Doctoral dissertation). Ankara University, Ankara.

Cerè, G., Rezgui, Y., Zhao, W. (2017). Critical review of existing built environment resilience frameworks: directions for future research. International journal of disaster risk reduction, 25, 173 189. Retrieved March 29, 2021, from: https://doi.org/10.1016/j.ijdrr.2017.09.018

Chambers, R. (1989). Vulnerability, coping and policy. Institue of Development Studies, 20(2):1-7. Retrieved March 29, 2021, from: https://opendocs.ids.ac.uk/opendocs/handle/20.500.12413/9551.

Cimellaro, G. P. (2016). Urban Resilience for Emergency Response and Recovery. Fundamental Concepts and Applications (Digitally). Switzerland : Springer International Publishing.

Critto, A. (2016). Climate change impacts, adaptation and vulnerability approaches [Powerpoint slides] Retrieved March, 13 2021, from: https://www.climamed.eu/wpcontent/uploads/files/Climate-Change-Impacts-Adaptation-and-VulnerabilityApproaches.pdf.

Dino, I. G. and C. M. Akgul (2019). "Impact of climate change on the existing residential 
building stock in Turkey: An analysis on energy use, greenhouse gas emissions and occupant comfort." Renewable Energy, 141: 828-846.

Disaster and Emergency Management Presidency. (2019). Types of disasters. Retrieved March 15, 2021, from: https://www.afad.gov.tr/afet-turleri.

DNV-GL. (2020) .B- Ready. Retrieved March 20, 2021 from: https://www.dnv.com/services/bready-106852.

Downing, T. E., Patwardhan, A., Klien, R., Mukhala, E., Stephen, L., Winograd, M., \& Ziervogel, G. (2003). Vulnerability assessment for climate adaptation. APF technical paper, 3.

Escarameia, M. and Tagg, A. (2021). Flood Resilience of Critical Buildings: Assessment Methods and Tools. In Climate Resilient Urban Areas (pp. 67-83). Palgrave Macmillan, Cham.

Fakhruddin, B., Boylan, K., Wild, A., \& Robertson, R. (2020). Chapter 12 - Assessing vulnerability and risk of climate change. In J. Sillmann, S. Sippel, \& S. Russo (Eds.), Climate Extremes and Their Implications for Impact and Risk. Assessment (pp. 217-241): Elsevier.

Folke, C. (2006). Resilience: The emergence of a perspective for social-ecological systems analyses. Global environmental change, 16(3), 253-267. Retrieved April 10, 2021 from: https://doi.org/10.1016/j.gloenvcha.2006.04.002

Gero, A.; Méheux, K.; Dominey-Howes, D. (2011). Integrating community based disaster risk reduction and climate change adaptation: examples from the Pacific. Natural Hazards and Earth System Sciences, 11, 101-113. Retrieved March 29, 2021, from:

https://doi.org/10.5194/nhess-11-101-2011.

Gero, A.; Méheux, K.; Dominey-Howes, D. (2011). Integrating disaster risk reduction and climate change adaptation in the Pacific. Climate and Development, 3, 310-327. Retrieved March 29, 2021, from: https://doi.org/10.1080/17565529.2011.624791.

Holling, C. S. (1996). Engineering resilience versus ecological resilience. Engineering within ecological constraints, 31(1996), 32. Retrieved from: https://books.google.com.tr/books?hl=en\&lr=\&id=qXxOAgAAQBAJ\&oi=fnd\&pg=PT3 9\&ots=1KThoDMnFu\&sig=uOsgnwC7XK4vkf.

Hosseini, S., Barker, K., Ramirez, M., Jose E. (2016). A review of definitions and measures of system resilience. Reliability Engineering and System Safety, Elsevier, vol. 145(C), pages 47-61. doi: $10.1016 /$ j.ress.2015.08.006

IPCC. Climate Change 2001: Impacts, Adaptation, and Vulnerability. In Contribution of WG II to the Third Assessment Report of the Intergovernmental Panel on Climate Change; Cambridge University Press: Cambridge, UK, 2001. Retrieved March, 26, 2021 from: https://www.ipcc.ch/site/assets/uploads/2018/05/SYR_TAR_full_report.pdf.

IPCC. (2007). Climate Change 2007: Mitigation. Contribution of Working Group III to the Fourth Assessment Report of the Intergovernmental Panel on Climate Change [B. Metz, O.R. Davidson, P.R. Bosch, R. Dave, L.A. Meyer (eds)], Cambridge University. Press, Cambridge, United Kingdom and New York, USA. Retrieved March 19, 2021, from: https://www.ipcc.ch/report/ar4/wg3/.

IPCC. (2014). Climate Change 2014: Impacts, Adaptation and Vulnerability. Contribution of Working 
Group III to the Fifth Assessment Report of the Intergovernmental Panel on Climate Change [Field, C.B., V.R. Barros, D.J. Dokken, K.J. Mach, M.D. Mastrandrea, T.E. Bilir, M. Chatterjee, K.L. Ebi, Y.O. Estrada, R.C. Genova, B. Girma, E.S. Kissel, A.N. Levy, S. MacCracken, P.R. Mastrandrea, and L.L.White (eds.)]. Cambridge University Press, Cambridge, United Kingdom and New York, NY, USA, pp. 1-32.

Kantamaneni, K. (2017). Assessing Coastal Vulnerability: Development of a Combined Physical and Economic Index. (Philosophy of Doctorate Thesis). University of Wales Trinity Saint David, United Kingdom.

Kelly, P.M., Adger, W.N. (2000). Theory and practice in assessing vulnerability to climate change and facilitating adaptation. Climate Change, 47, 325-352. Retrieved March 26, 2021, from: https://doi.org/10.1023/A:1005627828199.

Lei, Y.; Wang, J. (2014). A preliminary discussion on the opportunities and challenges of linking climate change adaptation with disaster risk reduction. Natural Hazards, 71, 1587-1597. Retrieved March 30, 2021 from: https://doi.org/10.1007/s11069-013-0966-6.

Lindsey, R. (2009). Climate and earth's energy budget. NASA Earth Observatory, 680.

McEntire, D., Crocker, C. G., \& Peters, E. (2010). Addressing vulnerability through an integrated approach. International Journal of Disaster Resilience in the Built Environment, 1 (1). Retrieved April 15, 2021, from: https://doi.org/10.1108/17595901011026472.

Onur, A.C. (2014). Evaluation of Urbanization in Istanbul in the Framework of Adaptation to Climate Change. (Doctoral dissertation). İstanbul Technical University, İstanbul.

Opach, T., Glaas, E., Hjerpe, M., Navarra, C. (2020). Vulnerability Visualization to Support Adaptation to Heat and Floods: Towards the EXTRA Interactive Tool in Norrköping, Sweden. Sustainability, 12(3), 1179. Retrieved March 28, 2021 from: https://doi.org/10.3390/su12031179.

Özdem, Y., Dal, B., Öztürk, N., Sönmez, D., \& Alper, U. (2014). What is that thing called climate change? An investigation into the understanding of climate change by seventh-grade students. International Research in Geographical and Environmental Education, 23(4), 294-313.

Papathoma-Köhle, M., Promper, C., Glade, T. (2016). A common methodology for risk assessment and mapping of climate change related hazards-implications for climate change adaptation policies. Climate, 4(1), 8. Retrieved April 1, 2021 from: https://doi.org/10.3390/cli4010008.

Pidgeon, N., Fischhoff, B. (2011). The role of social and decision sciences in communicating uncertain climate risks, Nature Climate Change 1, 35-41. Retrieved April 6, 2021 from: http://dx.doi.org/10.1038/nclimate1080.

Pievc Program (2018). Climate change impacts on the housing infrastructure at Oneida Nation of the Thames. Retrieved March 29, 2021, from: https://pievc.ca/2018/07/24/climate-change-impacts-on-thebousing-infrastructure-at-oneida-nation-of-the-thames/.

PreventionWeb (The knowledge platform for disaster risk reduction). (2015) .Disaster risk. Retrieved March 15, 2021, from: https://www.preventionweb.net/disasterrisk/risk/disaster-risk/. 
Rajkovich, N. B., Okour, Y. (2019). Climate Change Resilience Strategies for the Building Sector: Examining Existing Domains of Resilience Utilized by Design Professionals. Sustainability, 11(10). Retrieved April 5, 2021 from: https://doi.org/10.3390/su11102888

Redman, C.L. (2014). Should sustainability and resilience be combined or remain distinct pursuits? Ecology and Society,19, 1. Retrieved April 2, 2021 from: http://www.ecologyandsociety.org/vol19/iss2/art37/.

Republic of Turkey Ministry of Environment and Urbanization.(2018). Seventh national statement of Turkey. Retrieved July 13, 2021 from: https://webdosya.csb.gov.tr/db/cygm/icerikler/yed-nc--ulusal-b-ld-r-m20190909092640.pdf

Scribbr. (2020). Designing and analyzing Likert scales. Retrieved July 13, 2021, from: https://www.scribbr.com/methodology/likert-scale/

Smith, P. F. (2005). Architecture in a climate of change. Elsevier, Oxford, United Kingdom.

Tanik, A., Tekten, D. (2018). Planning Climate Change Adaptation Activities for Turkey. International Journal of Environmental Science and Development, 9(9). Retrieved April 2, 2021 from: https://doi.org/10.18178/ijesd.2018.9.9.1110

Thinkhazard. (2020). Turkey river flood. Retrieved March 28, 2021, from: https://thinkhazard.org/en/report/249-turkey/FL.

Thinkhazard. (2020). Turkey coastal flood. Retrieved March 28, 2021, from: https://thinkhazard.org/en/report/249-turkey/CF.

United Nations International Strategy for Disaster Reduction Secretariat. (2008). Climate Change and Disaster Risk Reduction. Retrieved March 13, 2021, from: https://www.unisdr.org/files/4146 ClimateChangeDRR.pdf.

UNFCC (2021). What do adaptation to climate change and climate resilience mean?. Retrieved July 15, 2021, from: https://unfccc.int/topics/adaptation-and-resilience/the-big-picture/what-doadaptation-to-climate-change-and-climate-resilience-mean.

UNDP (2002). A Climate Risk Management Approach to Disaster Reduction and Adaptation to Climate Change. Retrieved July 10, 2021, from: https://www.ipcc.ch/apps/njlite/srex/njlite download.php?id=7078.

Un-Spider Knowledge Portal. (2021). Disaster management. Retrieved March 18, 2021, from: https://www.un-spider.org/risks-and-disasters.

Viner, D, Ekstrom, M, Hulbert, M, Warner, NK, Wreford, A, Zommers, Z. (2020). Understanding the dynamic nature of risk in climate change assessments-A new starting point for discussion. Atmosferic Science Letters, 21:e958, Retrieved April 2, 2021 from: https://doi.org/10.1002/asl.958

Y1ldı, Y.(2012). Sensitivity and Uncertainty Analysis to Reduce Cooling Requirement of Lowrise Apartment Blocks in the Hot-Humid Climate Region of Turkey. (Doctoral dissertation). İzmir High Technology University, İzmir. 


\section{BIOGRAPHIES OF THE AUTHORS}

\section{Pelin SARICIOĞLU (Res. Asst.)}

Pelin Sarıcıoğlu is a research assistant at Gazi University as well as $\mathrm{PhD}$ student currently. She received her undergraduate degree from Faculty of Architecture, Karadeniz Technical University (Turkey). She got master degree from Gazi University (2015-2017), which is about "Kinetic Elements in Residential Design". Her ongoing PhD (2017-) subject is about "Climate change effects and disaster risk reduction". She studied as a PhD student in Poland for a semester, gained learning experience via Erasmus mobility, participated to several national / international congresses, wrote several articles in Turkish and English. Pelin Sarıcıoğlu can be contacted at: pelinsaricioglu@gazi.edu.tr.

\section{İdil AYÇAM (Assoc. Prof. Dr.)}

İdil Ayçam received her undergraduate and graduate degrees from Faculty of Architecture, Gazi University (Turkey). During her academic career in the same institute, participated to several national / international congresses, wrote several articles in Turkish and English as well as being member of Gazi Journal of Science editorial board, supervised several theses, conducted research projects funded by Ministry of Environment and Urban Planning and performed several administrative duties. Also, she won two prizes from a competition which name is "Interversity Thermal Insulation Competition” 2001 and 2003 respectively. İdil Ayçam can be contacted at: iaycam@gazi.edu.tr. 